\title{
Tipografia 3D: a proposição de uma fonte para o desenvolvimento de letras-caixa em papel
}

\section{D typography: proposing a font for the development of paper box letters}

Diego Alves de Oliveira Ribeiro, Renata Amorim Cadena

tipografia 3D, comunicação visual, materialidade

\begin{abstract}
A tipografia 3D vem alcançando espaço em projetos de comunicação visual, considerando aspectos esculturais e sensoriais provenientes da sua materialidade diversa. O presente artigo foi escrito a partir de um trabalho de conclusão de curso, que teve por objetivo desenvolver uma fonte tipográfica em papel, trazendo a discussão meio e materiais do fazer tipográfico, bem como as possíveis formas de se classificar as subcategorias da tipografia em três dimensões. Desse modo, este artigo tem por objetivo mostrar o processo de desenvolvimento da fonte Letras-Caixa A41000pt, que permite a criação de letras caixa em a partir de uma adaptação da metodologia de Cheng (2010).
\end{abstract}

\section{D Typography, Visual Communication, Materiality}

$3 D$ typography has been reaching attention in visual communication projects, due to its sculptural and sensorial aspects, intrinsic to its diverse materiality. This paper was made under an undergraduate final project, which aimed to develop a font that could be modelled three-dimensionally on paper, bringing the discussion on means and materials of the type making, as well as the possible ways of classifying the subcategories of 3D typography. Thus, this paper aims to show the development process of the Letras-Caixa A41000pt typeface, which allows the creation of uppercase letters from an adaptation of Cheng's (2010) method.

\section{Introdução}

Este artigo apresenta o processo de desenvolvimento de uma fonte tipográfica que possibilita a produção de letras caixa em papel. O desenvolvimento dessa fonte tem por objetivo facilitar o acesso a projetos planificados para serem impressos e posteriormente montados, tornando-se uma forma de contribuição para projetos de comunicação visual, de caráter profissional ou projeto cotidianos para a comunidade em geral.

Fontes digitais que trazem a planificação de letras para a produção tridimensional são escassas no mercado de fontes digitais, assim como métodos específicos para a construção da Curitiba | Brazil | 2021 
planificação e conferência de volumetria aos caracteres por meio de papel - com exceção de livros pop-ups ${ }^{1}$, que, no entanto, não foram o foco da pesquisa.

Identificamos que a tipografia, uma linguagem tradicionalmente bidimensional, faz correlação com a tridimensionalidade de três maneiras, que detalhamos nos parágrafos seguintes:

1. letras bidimensionais com o aspecto tridimensional;

2. letras bidimensionais posteriormente produzidas em materiais diversos; e

3. letras que são representações de objetos originalmente tridimensionais.

FI@ss (2011, P.8, tradução nossa) comenta que palavra 3D "é mais frequentemente usada para descrever algo que é realmente plano, mas tem o efeito, ou dá a ilusão, de profundidade" e está, de um modo geral, associada ao ambiente digital. Assim, os tipos 3D são, em geral, classificados como display.

A definição de 3D em tipografia pode ser estendida para uma abordagem de produção de produto, considerando artefatos e a criação deles, como na impressão 3D, no recorte de materiais de volumetria significativa e na produção de letras caixa. No nosso projeto, a palavra 3D assume uma definição em que a tipografia é apresentada como um objeto tridimensional expondo o 3D, deste modo, como não sendo "o efeito de três dimensões [..] Este é o tipo como objeto; físico e real" (Ibid, pp. 15-16, tradução nossa). Vale ressaltar que, no caso do nosso projeto, a volumetria foi projetada junto aos caracteres, mas é possível planejar o volume de maneira automática por meio de softwares, realizando posteriormente a impressão digital.

Refletindo sobre o aumento dos experimentos em tipografia 3D e os meios e materiais envolvidos, mas sobretudo com uma ênfase na produção de imagens tipográficas a partir de objetos, FI@ss (2011) propõe classificação da tipografia dos tipos 3D em três maiores grupos, são eles:

1. A Tipografia 3D "são aquelas que conseguem se apegar às convenções tipográficas, como altura-x, linha de base, proporções e assim por diante" (Ibid, p.13, tradução nossa) e que, em geral, são construídas fontes tipográficas a partir de imagens de artefatos.

2. O Lettering ${ }^{2} 3 D$ em que os objetos são reunidos e manipulados para formar letras ou palavras específicas, não há o intuito de construir uma fonte.

3. Nas performances tipográficas (3) se utiliza o corpo humano para formar letras. Usando meios como fotografia e videografia para a documentação.

Observamos que, apesar do crescente número de projetos que envolvem a tridimensionalidade como parâmetro principal para a tipografia, há uma escassez de bibliografias que mostre especificamente as classificações da tipografia 3D de forma detalhada. Garfield (2012) aponta que a atividade classificatória em tipografia é difícil em virtude da

\footnotetext{
1 "o termo estabelece ligação direta com o movimento provocado no objeto quando este é manuseado [por meio de] mecanismos da engenharia do papel como volantes alavancas ou linguetas" (Santos e Nojima, 2019)

${ }^{2}$ Lettering é "processo manual para a obtenção de letras únicas, a partir de desenhos" (Farias, 2004).
} 
diversidade de projetos, e que se trata de um esforço sobretudo mercadológico para facilitar a procura e a venda de fontes. Silva e Farias (2005) trazem um outro argumento, da importância dos sistemas de classificação para a padronização de termos, originalmente difusos em culturas tipográficas diversas.

Entendendo o contexto relativo ao mercado de fontes, da tipografia $3 \mathrm{D}$ e suas classificações, a fonte foi desenvolvida sob os aspectos relacionados às convenções tipográficas do grupo classificado como Tipografia 3D, em especial as fontes bidimensionais que se transformam em objetos tridimensionais. Para tal, uma adaptação da metodologia de Cheng (2010) foi adotada, valorizando a premissa da criação de uma lógica construtiva.

\section{Desenvolvimento}

O desenvolvimento da fonte foi possível através de uma adaptação da Metodologia proposta por Cheng (2010), da qual foram realizadas as seguintes etapas: Conceitualização, Definição de Parâmetros Tipográficos, Planificação mais a Digitalização. No caso, a digitalização da fonte foi realizada para reunir os caracteres em um único arquivo, facilitando o acesso. A Etapa de planificação foi introduzida antes da etapa de digitalização proposta por Cheng, para serem importados ao software FontLab $7^{3}$.

\section{Conceitualização}

Nessa etapa foram feitos rascunhos e pesquisas com o objetivo de reunir informações visuais necessárias para o desenho da fonte, a priori, digital. Uma questão que foi considerada nesta etapa foi a angularidade do desenho; quanto mais curvo, mais complexa a montagem, quanto mais retilíneo, menos adequado à produção plástica em papel. Portanto, o desenho da fonte se aproximou mais de um grid retangular.

Figura 1: Conceitualização do primeiro caractere, a letra A. Fonte: os autores.

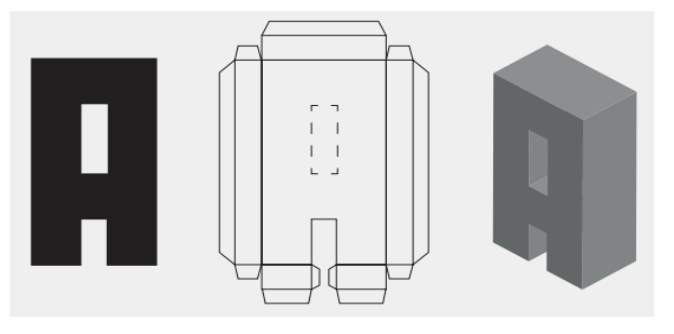

\section{Parâmetros Tipográficos}

A primeira consideração técnica a ser abordada é o desenho, nesse caso, a angulação que foi o fato de maior relevância, sendo todos os caracteres desenhos sem curvas. O segundo foram

\footnotetext{
${ }^{3}$ FONTLAB 7: software de edição de fonte tipográfica, Versão 7, FontLab Ltd. 2019. Disponível em: https://www.fontlab.com/font-editor/fontlab/. Acesso em: 21 de abril de 2020..
} 
problemas relacionados às similaridades entre caracteres que precisaram ser revistos, a exemplo do como o B e 8, 0 e O, que demandaram ajustes.

Figura 2: Fig. 2.a - Maiúsculas; Fig. 2.b - Minúsculas; Fig. 2.c - Numerais.

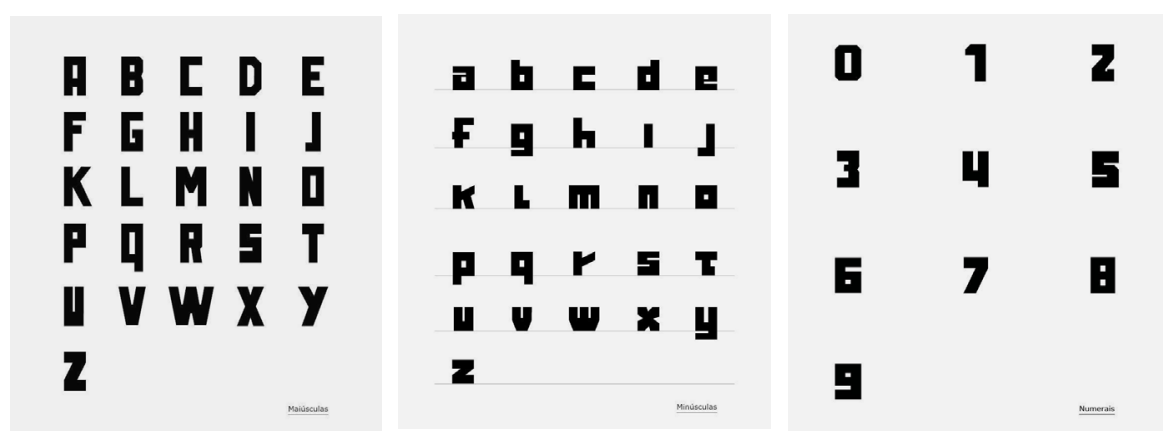

\section{Planificação}

Esse processo foi feito inteiramente no Adobe Illustrator CC $2020^{4}$, conferindo 2 centímetros de profundidade aos caracteres. Na construção foram verificadas três formas de se montar, são elas:

- Cúbica, em que se vinca, dobra e cola, utilizando as marcações dadas;

- Contorno, em que a peça que dá profundidade será colada inteiramente no contorno da face principal; e

- Mista, que é a união das duas formas, a caixa e o contorno, como foi verificado em letras como v, w, bem como em letras que possuem olhos, A, O, B, d, b.

Figura 3: Formas de montagem: Fig.3a - Cúbica; Fig. 3b - Mistas; Fig. 3c - Contorno. Fonte: Acervo dos próprios autores.
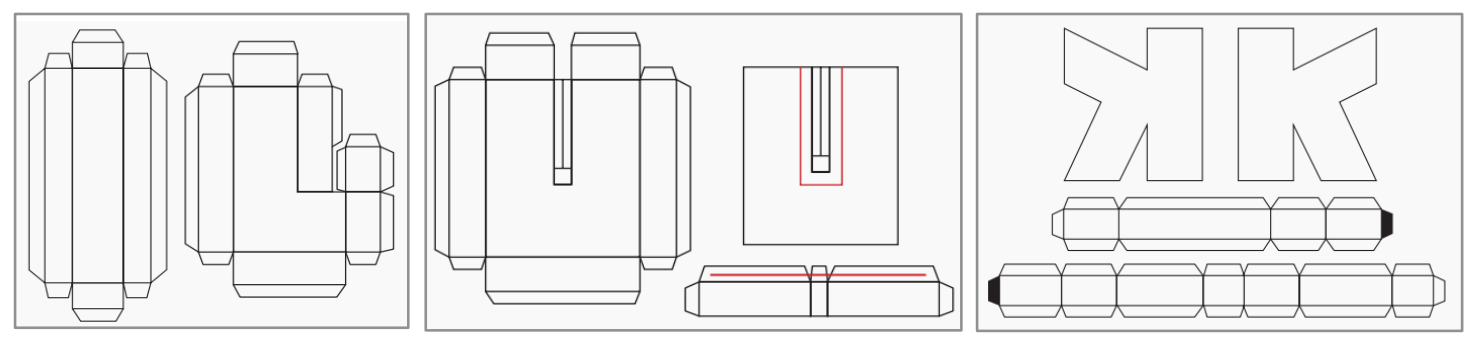

\section{Digitalização das planificações no Fontlab}

Apesar das letras terem sido criadas para a construção a partir de uma impressão em papel, visando facilitar o acesso a essas planificações esses caracteres foram do Adobe Illustrator para o FontLab, para a criação do arquivo de fonte. As Etapas foram as seguintes:

\footnotetext{
${ }^{4}$ ADOBE ILLUSTRATOR: software de desenho vetorial, Versão 2020 (24.1) Adobe Systems, 2020. Disponível em: https://www.adobe.com/br/products/illustrator.html. Acesso em: 04 de abril de 2020.
} 
1. Padronização da planificação no Adobe Illustrator, que foi feito adicionando um retângulo do tamanho nas proporções do formato de folhas ' $A$ ' a todos os caracteres. Esse processo facilitou o alinhamento dos arquivos na linha de base dos glifos no Fontlab, e manteve as planificações num tamanho padrão entre si, que é o tamanho da folha A4;

2. Importação e métricas, em que a importação foi feita através da cópia e colagem direta dos vetores. O processo de métricas foi feito adicionando um ajuste global de um total de 25 unidades para cada lado dos caracteres, dando um espaçamento entre letra para cada arquivo, no intuito de não sobrepor linhas; e

3. Exportação simples do arquivo digital.

Figura 4: Exemplo das letras $\mathrm{H}$ e $\mathrm{M}$ referentes ao espacejamento das planificações enquanto fonte digital.
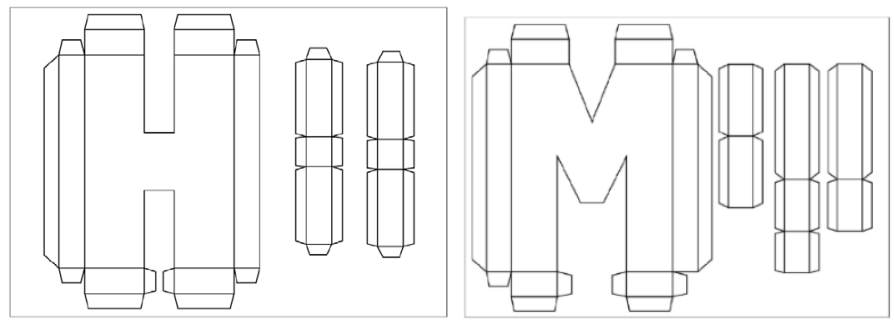

\section{Materiais de Consideração e Montagem}

O Material principal utilizado para a montagem é o papel, preferencialmente com gramatura a partir $240 \mathrm{gr}$, pois abaixo disso pode rasurar ou rasgar. Para a montagem, a cola bastão é a mais indicada, pois a líquida pode rasurar o papel ou manchar o papel. Além disso, recomendase o uso de tesoura para recortar os 'moldes' planificados, um estilete para cortar os olhos/ocos de determinados caracteres.

O Escalonamento dessas planificações para um tamanho menor que uma folha formato A4 pode prejudicar a montagem, visto que pode complicar o processo de vinco, de dobradura e de colagem. Portanto, recomenda-se o escalonamento para tamanhos maiores que A4. Para edição das letras em programas vetoriais é recomendado usar o tamanho de 1000pt, que é o padrão (referente ao formato A4) e logo depois expandir a linhas para objeto, para, em seguida, escalonar para um tamanho maior.

Figura 5: Exemplos de palavras com a fonte A41000pt
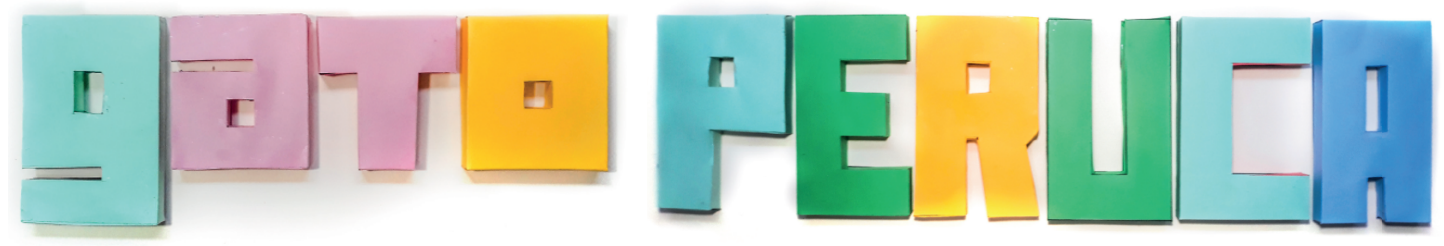


\section{Considerações Finais}

O processo de desenvolvimento de letras-caixa é um processo, a priori, técnico, pois envolve questões que se estendem da escolha do material até questões de dimensão mínima para ter um bom funcionamento.

Compreendemos, também, que disponibilizar as planificações como um arquivo digital favorece o acesso, auxilia na diminuição do arquivo (bits) e permite uma edição da fonte pelo design/usuário de forma direta em qualquer software de vetor ou edição de imagem.

Como bem coloca Jacques (2002, p. 9) é "exigido do comunicador visual, para atuar como voz ativa dentro deste sistema [social e cultura], um grande entendimento das questões relacionadas à cultura, à comunicação, à sociedade e ao meio ambiente". Assim, considerando o atual cenário de pandemia, esse projeto se coloca como não sendo somente um exercício prático e teórico, enquanto questões de, respectivamente, de desenvolvimento de fonte tipográficas e introdução às classificações tipográficas em três dimensões, mas coloca-se também como responsável por um produto social que, considerando o baixo custo de acesso ao material (se relacionados aos materiais tradicionais utilizados para as letras-caixa), permite facilitar o acesso a esse tipo de fonte em 3D com materiais acessíveis e viáveis economicamente.

\section{Referências}

Byrom, A. (2011). Prefácio. In: FI@ss, The 3D Type Book (pp. 12-13). Londres: Laurence King Publishing. Ebook Kindle.

Cheng, K. (2005) Designing Type. Yale: Yale University Press,

FI@ss. (2011) The 3D Type Book. Londres: Laurence King Publishing. E-Book Kindle.

Farias, P. L, \& Silva, F. L. C. M (2005) Um panorama das classificações tipográficas. In.

Estudos em Design. Vol. 11, n. 2. p. 67 - 81. Rio de Janeiro: USP.

Farias, P. L (2004). Notas para uma normatização da nomenclatura tipográfica. Anais do P\&D Design 2004. São Paulo: FAAP

Garfield, A.. (2012). Esse é o meu tipo: Um livro sobre fontes. 1. ed. Rio de Janeiro: Zahar. Jacques, J. P. (2002). Tipografia pós-moderna. Rio de Janeiro: 2AB, $3^{\mathrm{a}}$ ed.

Santos, V. S. \& Nojima, V. L. (2019). As funções de linguagem na construção narrativa do livro pop-up. $9^{\circ}$ Congresso Internacional de Design da Informação, Blucher Design Proceedings, Volume 6, 2019, pp. 213-221. Belo Horizonte.

\section{Sobre os autores}

Diego Alves de Oliveira Ribeiro, Tecnol., IFPB, Brasil <diegoaoliveirar@gmail.com> Renata Amorim Cadena, Dra. IFPB, Brasil, <renata.cadena@ifpb.edu.br> 